\title{
Determinants of frailty in primary care patients with COPD: the Greek UNLOCK study
}

Despo lerodiakonou ${ }^{1,2}$, Maria Kampouraki ${ }^{3}$, loannis Poulonirakis ${ }^{4}$, Polyvios Papadokostakis ${ }^{5}$, Eleftheria Lintovoi ${ }^{6}$, Dimitris Karanassos ${ }^{7}$, Kyriakos Maltezis ${ }^{7}$, Maria Chorti $^{8}$, Evangelos Petrovitsos ${ }^{8}$, Sofia Dimopoulou ${ }^{9}$, Sam Hamind ${ }^{10}$, Ioannis Gialamas ${ }^{11}$, Polyxeni Athanasiou ${ }^{2}$, Vasiliki Bempi ${ }^{2}$, Irene Lambraki ${ }^{2}$ and loanna Tsiligianni ${ }^{1 *}$

\begin{abstract}
Background: Frailty is a state of increased vulnerability that has a significant risk of unfavorable outcomes such as increased dependency and/or death, but little is known about frailty in people with chronic obstructive pulmonary disease (COPD).

Method: We aimed to determine the prevalence of frailty in COPD patients and to identify the associated risk factors. Two hundred fifty-seven COPD patients enrolled from primary care in Greece between 2015 and 2016. Physicians used structured interviews to collect cross-sectional data including demographics, medical history, symptoms and COPD Assessment Tool (CAT) or modified Medical Research Council Dyspnea scale (mMRC) score. Patients were classified into severity groups according to GOLD 2017 guidelines. Participants completed the The Frail Non-Disabled (FiND) questionnaire, exploring the frailty and disability domains. In the present analyses, frail patients with and without mobility disability were pooled and were compared to non-frail patients. Factors associated with frailty were analyzed using univariate and multivariate logistic regression.
\end{abstract}

Results: Mean (SD) age was 65 (12.3) with 79\% males. The majority of patients suffered with frailty (82\%) of which $76.8 \%$ had mobility disability. $84.2 \%$ were married/with partner and $55.4 \%$ retired. $55.6 \%$ were current smokers. Uncontrolled disease ( $\geq 10$ CAT score) was reported in $91.1 \%$ and $37.2 \%$ of patients had $\geq 2$ exacerbations in the past year. Dyspnea (38\%) and cough (53.4\%) were the main symptoms. Main comorbidities were hypertension (72. $9 \%)$, hyperlipidaemia (24.6\%) and diabetes (11\%).

Risk of frailty was significantly increased with age (OR; $95 \% \mathrm{Cl}: 1.05 ; 1.02-1.08)$, hypertension $(2.25 ; 1.14-4.45)$, uncontrolled disease ( $\geq 10$ CAT score 4.65; 1.86-11.63, $\geq 2$ mMRC score 5.75 (2.79-11.85) or $\geq 2$ exacerbations 1.73; 1.07-2.78), smoking cessation (ex compared to current smokers: $2.37 ; 1.10-5.28$ ) and GOLD status (B\&D compared to A\&C groups: CAT-based 4. 65; 1.86-11.63; mMRC-based: 5.75; 2.79-11.85). In multivariate regression smoking cessation and GOLD status remained significant. Gender, body mass index, occupational or marital status, symptoms and other comorbidities were not significant.

Conclusions: Frailty with mobility disability is common in COPD patients and severity of disease increases the risk. It is possible that frail patients are more likely to quit smoking perhaps because of their disability and uncontolled disease. Routine assessment of frailty in addition to COPD control may allow early interventions for preventing or delaying progression of frailty and improvement in COPD disease.

Keywords: COPD, Fraitly, Severity, Symptoms, Exacerbations, CAT, mMRC

\footnotetext{
*Correspondence: i.tsiligianni@uoc.gr

'Department of Social Medicine, Faculty of Medicine, University of Crete,

Voutes Campus, GR-71003 Heraklion, Crete, Greece

Full list of author information is available at the end of the article
}

(c) The Author(s). 2019 Open Access This article is distributed under the terms of the Creative Commons Attribution 4.0 International License (http://creativecommons.org/licenses/by/4.0/), which permits unrestricted use, distribution, and reproduction in any medium, provided you give appropriate credit to the original author(s) and the source, provide a link to the Creative Commons license, and indicate if changes were made. The Creative Commons Public Domain Dedication waiver (http://creativecommons.org/publicdomain/zero/1.0/) applies to the data made available in this article, unless otherwise stated. 


\section{Background}

Frailty is a known health problem of the senior population and of subjects suffering from chronic diseases that enhances the risk of adverse outcomes, including accidental falls, admissions to hospitals, institutionalization, and mortality [1-3]. The Frailty Consensus Conference defined physical frailty as "a medical syndrome with multiple causes and contributors that is characterized by diminished strength, endurance, and reduced physiologic function that increases an individual's vulnerability for developing increased dependency and/or death" [4]. Identifying frail older subjects living in the community has recently been well accepted as the cornerstone for preventing frailty's adverse health outcomes [5].

Even though the frequency of frailty may vary depending on the assessment method used, overall it is estimated to affect $10.7 \%$ of persons aged $\geq 65$ [6], and prevalence can be as high as $50 \%$ or greater depending on the frailty definition used $[7,8]$. Prevalence increases with age, female gender and with a higher number of comorbidities [6,9]. The shared underlying pathways linking frailty to aging and other chronic diseases remain unclear, but some of the proposed biological mechanisms include chronic systemic inflammation, musculoskeletal and neuroendocrine dysfunction [10, 11].

Chronic obstructive pulmonary disease (COPD) is a condition commonly resulting in vulnerable elderly populations. COPD is closely related to frailty with shared risk factors such as aging and smoking and common mechanisms of dysregulated inflammation and endocrine dysfunction [12]. Although primarily a lung disease, COPD is recognized to have extra-pulmonary effects, including musculoskeletal dysfunction, nutritional imbalance with weight loss, and cardiovascular events, among others $[13,14]$. Studies exploring the issue of frailty in COPD are fewer and those that exist, suggest that the prevalence of frailty is higher in COPD patients as compared to the general population; but the prevalence given in the different studies varies depending on the instrument used for screening and the population $[8,9,15]$. Galizia et al. reported that frailty increased the mortality risk by $80 \%$ in patients suffering from COPD, while Lahousse et al. suggested that in addition to COPD severity and comorbidities, frailty predicts risk of mortality $[9,16]$. Moreover frailty has been suggested as a risk factor of readmissions within 90 days of hospitalization for acute COPD exacerbations [17].

Multiple tools exist for screening of frailty in clinical settings but most of them are not designed to be self-administered $[18,19]$. If the screening has to target large populations, this may become an issue especially for longterm follow up in primary care. The "Frail non-Disabled" (FiND) questionnaire is constructed based on the widely used frailty phenotype (including 5 main criteria: unintentional weight loss (4.5 $\mathrm{kg}$ in past year), self-reported exhaustion, weakness (grip strength), slow walking speed, and low physical activity) [3], but it also includes a specific section for exploring the presence of mobility disability (an early stage of the disabling process). In a study the FiND questionnaire presented a good precision in identifying community dwelling frail older persons without mobility disability [20].

In the current cross-sectional study we used the FiND questionnaire in primary care settings and we aimed to determine the prevalence of frailty (with and without mobility disability)within COPD patients, and to identify population and disease characteristics that may increase the risk of frailty in COPD patients.

\section{Methods}

This study consists of the Greek national branch of the UNLOCK (Uncovering and Noting Long-term Outcomes in COPD and asthma to enhance Knowledge), an international collaboration between primary care researchers to coordinate and share datasets of relevant diagnostic and follow-up variables for COPD and asthma management in primary care. It was set up by members of International Primary Care Respiratory Group and the first author IT was responsible for developing the Greek database. The protocol summary was published in 2010 [21]. The study was approved by the local medical ethics committee of the University Hospital of Crete Greece (protocol number 7985), and the patients gave written informed consent.

A sample of 257 COPD patients was enrolled between 2015 and 2016 from 53 primary care facilities in Greece. A convenient sampling method was used to select COPD patients living in rural and semi-urban areas served by primary care facilities across Greece. The participation rate among areas varied from 78 to $91 \%$. General practitioners with structured interviews collected cross-sectional information including demographic characteristics, medical history, lifestyle, respiratory symptoms, annual number of exacerbations and hospitalisations due to respiratory illness, and medication used for COPD management. The COPD Assessment Test (CAT) [22] and Modified Medical Research Council (mMRC) Dyspnea Scale [23] were completed and scores were calculated. COPD patients were classified according to Global Initiative for Chronic Obstructive Lung Disease (GOLD) 2017 guidelines e.g., ABCD grading system [24]. The $A B C D$ grading system considers $C O P D$ health status, assessed by CAT or mMRC, along with exacerbation frequency and need for hospitalisation (A is better, D is worse). We classified COPD patients to A-D groups based on both CAT and mMRC tools.

For screening for frailty, participants completed the FiND questionnaire [20], including frailty and disability domains. The FiND is a tool designed to be applied in the community and primary care, can be self-administered, be 
completed in approximately $1 \mathrm{~min}$, and it does not require record data or clinical assessment [25]. We also selected the FiND questionnaire as a tool for measuring frailty because we aimed to identify COPD subjects at an early stage of the syndrome (e.g. without mobility disability). The FiND questionnaire consists of five different questions/items (Table 1). Two questions are specifically aimed at identifying individuals with mobility disability (items A and B). Three additional questions assess conditions commonly considered as components of the frailty syndrome [3] (items C: weight loss, D: exhaustion and E: sedentary behaviour). If $A+B \geq 1$, the individual is considered as "disabled". If $\mathrm{A}+\mathrm{B}=0$ and $\mathrm{C}+\mathrm{D}+\mathrm{E} \geq 1$, the individual is considered as "frail". Patients positive for disability could also be positive for frailty. If $A+B+C+D+E=0$, were considered as "robust" (without frailty or disability) at the FiND questionnaire. In the present analyses, disabled and frail (without mobility disability) patients were pooled and were compared to robust patients.

\section{Statistical analysis}

Descriptive statistics were presented as a percentage for categorical variables and as mean (standard deviation) for normally distributed variables or as median (minimum-maximum) for continuous variables without a normal distribution. Correlation between CAT and mMRC scores were tested with Pearson Rho coefficient. Chi-square test and T-tests or Mann-Witney tests were used to identify differences between frail and robust COPD patients for qualitative or quantitative variables respectively. A $P$-value of $<0.05$ was considered a statistically significant difference. Effects of the factors associated with frailty were evaluated using univariate and multivariate logistic regression analyses. In univariate analysis, crude odds ratio (OR) and $95 \%$ confidence intervals $(95 \% \mathrm{CI})$ was used to examine the strength of association of the factors examined with frailty. Factors with a $P$-value of $<0.05$ were then entered into a multivariate logistic regression model and adjusted OR $(95 \% \mathrm{CI})$ was used to determine whether significant factors are independent from each other. Data management and statistical analyses were performed in IBM-SPSS Statistics software (version 23).

\section{Results}

The main population characteristics are presented in Table 2. Mean (SD) population age was 65 (12.3) with 204 (79.4\%) males. The majority were married/with partner (208 (84.2\%)) and retired (123 (55.4\%)). One hundred and forty three $(55.6 \%)$ were current smokers. CAT score was positively correlated with $\mathrm{mMRC}$ score $(\mathrm{rho}=0.55$; $p$-value $<0.001)$. With the use of CAT and mMRC tools, uncontrolled/poor health status was reported in 224 (91.1\%) and 154 (60.6\%), respectively. Seventy seven (37.2\%) of the patients had at least 2 exacerbations in the last 12 months. Based on GOLD 2017 guidelines, group B was the largest followed by groups D, A and C. The majority of patients reported dyspnea $(135(53.4 \%))$ as their main symptom, followed by cough (96 (37.9\%)). Most subjects suffered from cardiometabolic diseases such as hypertension (186 (72.9\%)), hyperlipidemia (63 (24.6\%)) and type II diabetes mellitus (28(11\%)).

Two hundred and fifty three COPD patients had complete FiND data. In the analysis $45(17.8 \%)$ robust subjects were compared to a pooled group of 208 (82.2\%) patients including: 15 (6\%) frail subjects without

Table 1 The "Frail non-Disabled" (FiND) questionnaire

\begin{tabular}{|c|c|c|c|}
\hline Domain & Questions & Answers & Score \\
\hline \multirow[t]{4}{*}{ Disability } & \multirow[t]{2}{*}{ A. Have you any difficulties at walking $400 \mathrm{~m}$ ? } & a. No or some difficulties & 0 \\
\hline & & b. A lot of difficulties or unable & 1 \\
\hline & \multirow[t]{2}{*}{ B. Have you any difficulties at climbing up a flight of stairs? } & a. No or some difficulties & 0 \\
\hline & & b. A lot of difficulties or unable & 1 \\
\hline \multirow[t]{6}{*}{ Frailty } & \multirow[t]{2}{*}{ C. During the last year, have you involuntarily lost more than $4.5 \mathrm{~kg}$ ? } & a. No & 0 \\
\hline & & b. Yes & 1 \\
\hline & \multirow{2}{*}{$\begin{array}{l}\text { D. How often in the last week did you feel than everything you did } \\
\text { was an effort or that you could not get going? }\end{array}$} & a. Rarely or sometime (twice or less/week) & 0 \\
\hline & & b. Often or almost always (3 or more times per week) & 1 \\
\hline & \multirow[t]{2}{*}{ E. Which is your level of physical activity? } & a. Regular physical activity (at least 2-4 $\mathrm{h}$ per week) & 0 \\
\hline & & b. None or mainly sedentary & 1 \\
\hline
\end{tabular}

Items $A$ and $B$ define disability domains and items $C, D$ and $E$ define frailty domains. If $A+B \geq 1$, the individual is considered as "disabled". If $A+B=0$ and $C+D+$ $E \geq 1$, the individual is considered as "frail". Participants reporting no mobility disability as well as no frailty criterion e.g. If $A+B+C+D+E=0$, are considered as "robust" (non-frail). Subjects positive for disability could also have positive frailty domains

Table adopted by Cesari et al. [20] 
Table 2 Population characteristics

\begin{tabular}{|c|c|c|c|c|}
\hline & TOTAL & NON-FRAIL & FRAIL-DISABLE & $\begin{array}{l}P- \\
Y A \| E^{a}\end{array}$ \\
\hline & $N=257$ & $N=45(18 \%)$ & $N=208(82 \%)^{b}$ & \\
\hline Age; mean (SD) & $65(12.3)$ & $57.3(11.3)$ & $64.7(11.6)$ & $<0.001$ \\
\hline BMl; mean (SD) & $29(5.3)$ & $29(4.7)$ & $29(5.3)$ & 0.849 \\
\hline Males; n (\%) & $204(79.4)$ & $36(80.0)$ & $162(79.0)$ & 0.884 \\
\hline Marital status; n (\%) & & & & 0.005 \\
\hline Married/with partner & $208(84.2)$ & $35(81.4)$ & $171(85.1)$ & \\
\hline Widower & $24(9.7)$ & $1(2.3)$ & $22(10.9)$ & \\
\hline Divorced or never married & $15(6.1)$ & $7(16.3)$ & $8(4.0)$ & \\
\hline Occupational status; n (\%) & & & & 0.088 \\
\hline Employed & $74(33.3)$ & $17(45.9)$ & $53(29.4)$ & \\
\hline Unemployed/housewife & $25(11.3)$ & $5(13.5)$ & $20(11.1)$ & \\
\hline Retired & $123(55.4)$ & $15(40.5)$ & $107(59.4)$ & \\
\hline Smoking status; n (\%) & & & & 0.091 \\
\hline Current & $143(55.6)$ & $31(68.9)$ & $106(51.7)$ & \\
\hline Ex & $83(32.3)$ & $9(20.0)$ & $73(35.6)$ & \\
\hline Never & $31(12.1)$ & $5(11.1)$ & $26(12.7)$ & \\
\hline Pack-years; median (min-max) & $40(10-200)$ & $40(20-100)$ & $40(10-200)$ & 0.197 \\
\hline Main symptom; n (\%) & & & & 0.458 \\
\hline Cough & $96(37.9)$ & $15(34.1)$ & $76(37.4)$ & \\
\hline Dyspnea & $135(53.4)$ & $23(17.2)$ & $111(54.7)$ & \\
\hline Else (Wheezing, chest tightness, phlegm) & $22(8.7)$ & $6(13.6)$ & $16(7.9)$ & \\
\hline CAT symptom severity; $\mathrm{n}(\%)$ & & & & 0.002 \\
\hline$<10$ & $22(8.9)$ & $10(23.3)$ & $12(6.1)$ & \\
\hline$\geq 10$ & $224(91.1)$ & $33(77.7)$ & $184(93.9)$ & \\
\hline mMRC symptom severity; $\mathrm{n}(\%)$ & & & & $<0.001$ \\
\hline $0-1$ & $100(39.4)$ & $33(73.3)$ & $66(32.4)$ & \\
\hline$\geq 2$ & $154(60.6)$ & $12(26.7)$ & $138(67.6)$ & \\
\hline Number of exacerbations in the last 12 months; median (mix-max) & $1(0-4)$ & $1(0-2)$ & $1(0-4)$ & 0.033 \\
\hline Number of hospitalisation in the last 12 months; median (min-max) & $0(0-3)$ & 0 & $0(0-3)$ & 0.100 \\
\hline GOLD 2017 - CAT; n (\%) & & & & 0.003 \\
\hline A & $11(5.4)$ & $5(14.3)$ & $6(3.6)$ & \\
\hline B & $115(56.4)$ & $21(60.0)$ & $90(54.5)$ & \\
\hline C & $3(1.5)$ & $2(5.7)$ & $1(0.6)$ & \\
\hline $\mathrm{D}$ & $75(36.8)$ & $7(20.0)$ & $68(41.2)$ & \\
\hline GOLD 2017 - mMRC; n (\%) & & & & $<0.001$ \\
\hline A & $57(27.5)$ & $18(50.0)$ & $39(23.1)$ & \\
\hline B & $71(34.3)$ & $9(25.0)$ & $60(35.5)$ & \\
\hline C & $20(9.7)$ & $7(19.4)$ & $13(7.7)$ & \\
\hline $\mathrm{D}$ & $59(28.5)$ & $2(5.6)$ & $57(33.7)$ & \\
\hline Type II Diabetes Mellitus; n (\%) & $28(11.0)$ & $3(6.7)$ & $25(12.3)$ & 0.279 \\
\hline Hypertension; n (\%) & $186(72.9)$ & $26(59.1)$ & $156(76.5)$ & 0.018 \\
\hline Hyperlipidaemia; n (\%) & $63(24.6)$ & $10(22.2)$ & $51(25.0)$ & 0.695 \\
\hline Coronary Heart Disease; n (\%) & $32(12.5)$ & $2(4.4)$ & $30(14.7)$ & 0.063 \\
\hline Thyroid disorder; n (\%) & $19(7.4)$ & $4(8.9)$ & $15(7.4)$ & 0.757 \\
\hline
\end{tabular}


Table 2 Population characteristics (Continued)

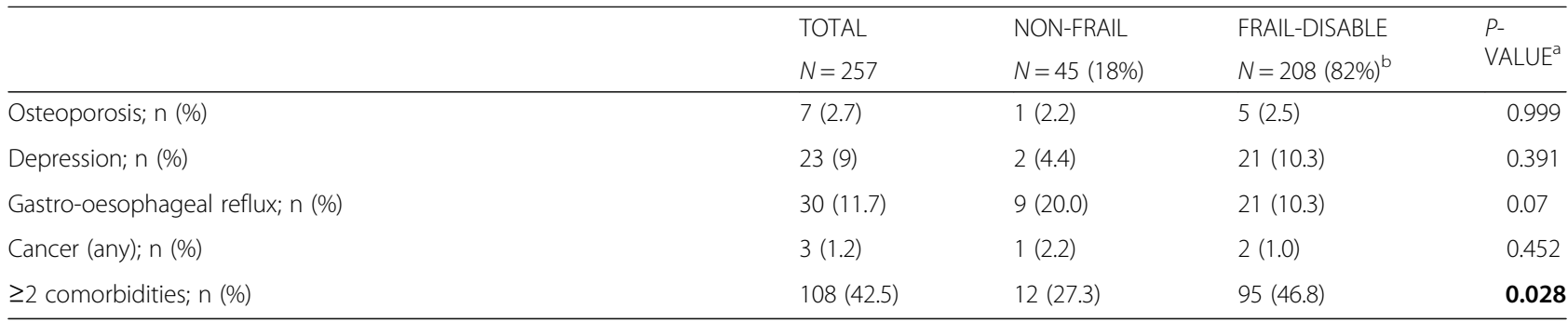

${ }^{\mathrm{a}} \mathrm{P}$-value is given by Chi-square test or Fisher exact test for categorical variables and by T-test for normally distributed variables (age, BMI) or Mann Witney test for not normally distributed variables

booled group of $208(82.2 \%)$ patients including: 15 (6\%) frail subjects without disability, $162(64 \%)$ frail with mobility disability and 31 (12.2\%) subjects with mobility disability only. Disabled group as defined by FiND $(A+B \geq 1)$ consisted of the latter two groups $(n=193(76.2 \%))$

Bold faceted $P$-values show significant associations (P-value<0.05). GOLD 2017: Global Initiative for Obstructive Lung Disease 2017 Guidelines, CAT: Chronic Obstructive Pulmonary Disease Assessment Test, mMRC: Modified Medical Research Council Dyspnoea Scale, BMI: body mass index

disability, $162(64 \%)$ frail with mobility disability and 31 (12.2\%) subjects with mobility disability only. Disabled group as defined by FiND $(\mathrm{A}+\mathrm{B} \geq 1)$ consisted of the latter two groups $(n=193(76.2 \%))$. Frailty was associated with age, hypertension, number of comorbidities, uncontrolled disease and number of exacerbations as well as with GOLD A-D status (Table 2). These associations remained significant when 3 groups were compared e.g., robust, frail, disabled (data not shown). Results of univariate logistic regression are presented in Table 3. Risk of frailty was significantly increased with age (OR $(95 \% \mathrm{CI}) 1.05$ (1.02-1.08) per year), hypertension (OR $(95 \% \mathrm{CI}) 2.25$ (1.14$4.45)$ ), $\geq 2$ comorbidities (OR (95\%CI) 2.35 (1.14-4.81)), uncontrolled disease (OR $(95 \% \mathrm{CI})$ for $\geq 10$ CAT score 4.65 (1.86-11.63), or $\geq 2 \mathrm{mMRC}$ score 5.75 (2.79-11.85), or $\geq 2$ exacerbations 1.73 (1.07-2.78)), smoking cessation (ex-smokers vs. current smoking: OR (95\%CI) $2.37(1.10-5.28)$ ) and GOLD B\&D status (OR (95\%CI) CAT-based: (4.65 (1.8611.63); mMRC-based: 5.75 (2.79-11.85)). In a multivariate analysis (Table 4) only smoking cessation and GOLD status remained significant. To identify which component of GOLD stage (exacerbations or health status) was the main determinant of frailty we included in the multivariate regression CAT or mMRC score and exacerbations instead of CAT- or mMRC-based GOLD disease status. This sensitivity analyses showed that in the model including mMRC score and exacerbations the main significant determinant of frailty was mMRC (mMRC $P=0.001$ and exacerbations $P=0.124)$. In the model including CAT score and exacerbations, both had a borderline significant association $(P=0.063)$. Multivariate analysis including $\geq 2$ comorbidities instead of hypertension did not alter the results. Gender, BMI, occupation, symptom type or time and other comorbidities were not significant.

\section{Discussion}

The objectives of the present study were to determine the prevalence of frailty in COPD patients visiting primary care facilities in Greece, and to identify the associated risk factors. Using the FiND questionnaire we found that frailty affects $82 \%$ of Greek COPD patients with a mean age of 67 years old, with the great majority of frail subjects suffering from mobility disability. The prevalence of frail-disabled COPD patients increased with age, GOLD stage or uncontrolled disease (CAT or mMRC or exacerbations), smoking cessation and comorbidities, but only GOLD stage and smoking cessation remained significant in multivariable analysis.

In out study the prevalence of frailty in COPD was greater compared to other populations, however this may be attributed to different definitions of frailty used and variation in population's mean age, therefore it may be difficult to compare prevalence across studies. Several studies show that the prevalence of pre-frailty (defined as the presence of 1 or 2 modified Fried criteria [3]) is around 47\% but reported prevalence of frailty in the general population and COPD enormously varied (range 4.0-74\%) $[6,15,18]$. A study using survey data found that $57 \%$ of COPD patients suffered from frailty [8]. A general Dutch population of community-dwelling elderly able to perform the frailty tests, showed that 163 (5.8\%) participants were frail and 1454 (51.3\%) pre-frail [9]. In another cross-sectional study of COPD patients in Southeast Asia the occurrence of frailty and pre-frailty were 6.6 and $41.3 \%$ respectively [26]. In our study, the population was recruited in rural areas in Greece, where the living environment may contribute to the frailty profile, thus potentially affecting our findings. Nevertheless, the FiND questionnaire [20] used in our study includes 3 of the 5 original criteria (i.e. involuntary weight loss, low physical activity and exhaustion) of the frailty phenotype widely used making it very similar.

The FiND questionnaire is to support the identification of community-dwelling older persons presenting an increased risk of frailty in the early stage of the syndrome e.g., before developing mobility disability [20]. Unfortunately, we showed that the majority of COPD subjects in our study already had developed mobility disability, suggesting that screening of frailty in patients with COPD should start early and 
Table 3 Univariate analyses of frailty association with patient characteristics

\begin{tabular}{|c|c|}
\hline & Crude OR $(95 \% \mathrm{Cl})$ \\
\hline Age (years) & $1.05(1.02-1.08)$ \\
\hline \multicolumn{2}{|l|}{ Marital status } \\
\hline Married/with partner & ref. \\
\hline Widow/Divorced/Never married & $0.77(0.33-1.81)$ \\
\hline \multicolumn{2}{|l|}{ Occupational status } \\
\hline Currently Employed & ref. \\
\hline Retired/Unemployed/Housewife & $2.04(0.99-4.19)$ \\
\hline \multicolumn{2}{|l|}{ Smoking status } \\
\hline Current & ref. \\
\hline Ex & $2.37(1.07-5.28)$ \\
\hline Never & $1.52(0.54-4.29)$ \\
\hline Hypertension & $2.25(1.14-4.45)$ \\
\hline Coronary Heart Disease & $3.71(0.85-16.12)$ \\
\hline Gastro-oesophageal reflux & $0.46(0.19-1.08)$ \\
\hline$\geq 2$ comorbidities & $2.35(1.14-4.81)$ \\
\hline \multicolumn{2}{|l|}{ CAT symptom severity } \\
\hline$<10$ & ref. \\
\hline$\geq 10$ & $4.65(1.86-11.63)$ \\
\hline \multicolumn{2}{|l|}{ mMRC symptom severity } \\
\hline $0-1$ & ref. \\
\hline$\geq 2$ & $5.75(2.79-11.85)$ \\
\hline \multicolumn{2}{|c|}{ Number of exacerbations in the last 12 months } \\
\hline$<2$ & ref. \\
\hline$\geq 2$ & $1.73(1.07-2.78)$ \\
\hline \multicolumn{2}{|l|}{ GOLD 2017 - CAT } \\
\hline$A \& C$ & ref. \\
\hline$B \& D$ & $5.64(1.83-17.33)$ \\
\hline \multicolumn{2}{|l|}{ GOLD 2017 - mMRC } \\
\hline$A \& C$ & ref. \\
\hline$B \& D$ & $5.11(2.34-11.16)$ \\
\hline
\end{tabular}

GOLD 2017: Global Initiative for Obstructive Lung Disease 2017 Guidelines, CAT: Chronic Obstructive Pulmonary Disease Assessment Test, mMRC: Modified Medical Research Council Dyspnoea Scale. ref.: reference group Bold faceted OR $(95 \% \mathrm{Cl})$ shows significant associations $(P$-value $<0.05)$

must be performed in multiple occasions to assess frailty status stage over time.

A prospective cohort study from respiratory outpatient and pulmonary rehabilitation clinics in the United Kingdom examined whether frailty affects completion and outcomes of pulmonary rehabilitation and found that frail patients had a two fold greater risk of programme non-completion. However, frailty could be reversed in the short-term in frail patients who managed to complete rehabilitation [27]. This promotes the idea of focusing more on pulmonary rehabilitation, and selecting rehabilitation approaches which may have components shared with
Table 4 Multivariate analysis of frailty association with patient characteristics

\begin{tabular}{lll}
\hline & $\begin{array}{l}\text { GOLD 2017 CAT } \\
\text { adjusted OR (95\%Cl) }\end{array}$ & $\begin{array}{l}\text { GOLD 2017 mMRC } \\
\text { adjusted OR (95\%Cl) }\end{array}$ \\
\hline Age (years) & $1.03(0.99-1.08)$ & $1.04(0.99-1.08)$ \\
Smoking status & & \\
Current & ref. & ref.
\end{tabular}

Ex $\quad 3.78(1.19-12.02) \quad 3.32(1.03-10.71)$

Never

$2.19(0.44-10.86)$

$1.39(0.34-5.67)$

Hypertension

$0.66(0.27-1.65)$

$0.48(0.19-1.22)$

GOLD 2017 - CAT

A\&C

ref.

$\mathrm{Na}$

$B \& D$

$3.95(1.09-14.34)$

GOLD 2017 - mMRC

A\&C na ref.

$B \& D$

$5.21(2.19-12.44)$

na: not applicable, ref.: reference group, GOLD 2017: Global Initiative for Obstructive Lung Disease 2017 Guidelines, CAT: Chronic Obstructive Pulmonary Disease Assessment Test, mMRC: Modified Medical Research Council Dyspnoea Scale. Bold faceted OR $(95 \% \mathrm{Cl})$ shows significant associations $(P$-value $<0.05)$

treatments proposed for frailty management including exercise, nutritional support, self-management strategies and reduction of polypharmacy [4].

A UK study showed that prevalence of frailty increased with age, GOLD stage, mMRC score and age-adjusted comorbidity burden [27]. Our study findings confirmed the aforementioned risk factors. Similarly Park et al. and Lahouse et al. showed that individuals with COPD who were older, had self-reported shortness of breath and comorbidities had increased risk of becoming frail, and frail people tended to have more disabilities $[8,9]$.

In COPD, shortness of breath and severity of symptoms may be linked to reduced physical activity, which may result in loss of muscle mass and strength, problems with mobility, therefore leading to frailty $[27,28]$.

We found that health status (CAT or mMRC scores) is a stronger predictor of frailty compared to the number of exacerbations. This may reflect the fact that frailty depends more on the long-term health status of COPD patients with its associated physical inactivity and muscle weakness, rather than on the short-term effect of change in physical activity due to an exacerbation. Identifying frailty early in the course of disease is important, as interventions can then be introduced to try to prevent further decline, hospital admission or death in those at high risk. Likewise, pulmonary rehabilitation should be introduced as early as possible in the course of COPD disease, for preventing or reversing frailty in COPD subjects.

Importantly, BMI did not differ significantly between frailty groups, which is similar to previous findings [9, 26, 29, 30], suggesting that 'sarcopenic obesity' might be a risk factor of frailty. 'Sarcopenic obesity' is the condition where lean body 
mass is lost, while fat mass may be preserved or even increased [31]. Thus muscle weakness may be attributed not only to loss of muscle tissue, but also to fat accumulation.

According to several reports, frailty increases with age [6]. Our study and a cross-sectional study in Thailand [26] showed that association with age did not remain significant in multivariate regression. This may suggest that it is the decline in respiratory function as we age that may increase the risk of frailty and not the age per se.

Similarly, hypertension was found to be a significant predictor of frailty in univariate logistic regression, but did not remain significant in adjusted models. We also observed a significant association between frailty and the number of comorbidities, which is consistent with other findings $[3,9,26$, 27]. A clear distinction between frailty and comorbidity has been described in the literature [1]. Frailty and comorbidity may interact and there can be synergistic effects on health-related outcomes, when frailty and comorbidity coexist.

A systematic review in 2015 including five cohort studies on smoking and frailty showed that baseline smoking significantly increased the risk for a worse frailty status at follow-up, even though most of the studies included had different methodology and frailty criteria used. The authors also reported that smoking cessation may potentially be beneficial for preventing or reversing frailty [32]. However, all of the studies compared never smokers with current or ex or ever smokers (current and ex smokers pooled). None of the studies compared frailty between ex and current smokers as we did. In our study never smoking was not associated with reduced risk of frailty compared to current smokers but ex-smokers were more likely to have frailty/disability than current smokers. We hypothesized that this may be due to the fact that our patients were extremely frail with an impaired health status and exacerbations, and they may be more likely to make the decision to quit smoking.

\section{Strengths and limitations of the study}

This study enrolled patients from usual consultations in primary care independent of the disease severity, therefore findings may be applicable to a wider population. However, most of the primary care facilities in Greece until 2016 were based in semi-urban or rural areas which may limit the external validity of the study, and may not reflect the management from secondary-tertiary care. The FiND questionnaire, used in this study to screen frailty, is originally validated in patients above the age of 60 only, but in the current study we also included patients younger than 60 years old. Most of the existing tools that screen for frailty are validated in elderly or very elderly general populations and most of them are not designed to be self-administered $[18,19]$. Although frailty has been associated with multimorbidity in the general population, studies exploring the issue of frailty in COPD are fewer, and some of those includes subjects younger than 60 years old [15]. However in the majority of observational studies the Fried criteria were used [15]. As we could not find any self-administered, community screening tool that had been validated in COPD or in middle age Caucasian adults, we decided to keep younger COPD subjects in the current analysis as in previous studies. However, FiND categorisation of COPD patients resulted in a very small group of frail subjects, therefore we had to pool those with the disabled patients group. Even though the majority of COPD subjects suffering with mobility disability were also frail based on FiND, our approach may limit the external validity of our study. Furthermore, the COPD diagnosis was based on patient records, therefore introducing risk of misclassification bias. Unfortunately, this study is cross-sectional in nature; thus, we were unable to explain the causal relationship between frailty and the identified risk factors.

Nevertheless, this study may have implications on clinical practice and public health as it the first study in Greece showing that frailty with mobility disability is common among COPD patients, and one of the first studies suggesting that severity of COPD disease increases the risk of frailty, while frail patients are more likely to quit smoking because of their disease severity.

\section{Implications of the study}

The importance of assessing frailty in elderly patients and in those with multimorbidity has been included in several guidelines such as the National Institute for Health and Care Excellence (NICE) (for multimorbidity) [33] and joint actions on the management of other chronic diseases such as diabetes [34]. Frailty however is a neglected area of research and implementation in daily clinical practice in respiratory diseases. Given that the clinical impact of patients with frailty could be reversed with early interventions (especially at the pre-disable stage), early recognition of this syndrome among COPD patients is critical. Routinely, assessing frailty by a structured questionnaire in addition to the CAT, mMRC could provide additional important information to the doctors and allow early interventions, including physical and respiratory rehabilitation, referrals to geriatric and nutritional specialists, to take place. This could potentially prevent or delay the progression of frailty and improve COPD.

\section{Conclusions}

Frailty with mobility disability is common in COPD patients and severity of disease increases the risk. Therefore routine assessment of frailty in addition to COPD control may allow for early interventions which may help delay progression of frailty and improve in COPD disease.

\section{Abbreviations}

BMI: body mass index; CAT: COPD Assessment Test; COPD: chronic obstructive pulmonary disease; FiND: Frail non-Disabled questionnaire; GOLD: Global Initiative for Chronic Obstructive Lung Disease; 
mMRC: Modified Medical Research Council Dyspnea Scale; UNLOCK: Uncovering and Noting Long-term Outcomes in COPD and asthma to enhance Knowledge

\section{Acknowledgements}

Not applicable.

\section{Funding}

This study was funded through a research grant from IPCRG to develop a Greek UNLOCK database and to analyse the findings. IPCRG has advised in design.

\section{Availability of data and materials}

The datasets generated and/or analysed during the current study are not publicly available due confidentiality agreement but are available from the corresponding author on reasonable request as long as the request meets the ethics.

\section{Authors' contributions}

IT was involved in the original concept and design of this article and supervised the whole project. MK was responsible for the data collection coordination. DI contributed significantly in data management and statistical analysis. All authors participated in different parts of the concept, design and data collection and entry, revised the article critically for important intellectual content and gave their final approval of the version to be published.

\section{Ethics approval and consent to participate}

All subjects signed a consent form and ethical approval was provided by the University of Crete Ethics Committee.

\section{Consent for publication}

Not applicable.

\section{Competing interests}

The authors have no competing interests to declare, financial or otherwise related to this publication.

\section{Publisher's Note}

Springer Nature remains neutral with regard to jurisdictional claims in published maps and institutional affiliations.

\section{Author details}

'Department of Social Medicine, Faculty of Medicine, University of Crete, Voutes Campus, GR-71003 Heraklion, Crete, Greece. ${ }^{2}$ Heraklion University Hospital, Heraklion, Crete, Greece. ${ }^{3}$ Primary care practice, Health Center of Moires, Heraklion, Crete, Greece. ${ }^{4}$ Primary care practice, Health Center of Agia Varvara, Heraklion, Crete, Greece. ${ }^{5}$ Primary care practice, Garipa, Herkalion, Crete, Greece. ${ }^{6}$ Primary care practice, Corfu, Greece. ${ }^{7}$ Primary care practice, Akraifnio, Boeotia, Greece. ${ }^{8}$ Primary care practice, Attica, Greece. ${ }^{9}$ Primary care practice, Chalkidiki, Greece. ${ }^{10}$ Primary care practice, Santorini, Cyclades Islands, Greece. ${ }^{11}$ Primary care practice, Health Center of Sitia, Sitia General Hospital, Lasithi, Crete, Greece.

\section{Received: 13 June 2018 Accepted: 26 February 2019}

Published online: 15 March 2019

\section{References}

1. Fried LP, Ferrucci L, Darer J, Williamson JD, Anderson G. Untangling the concepts of disability, frailty, and comorbidity: implications for improved targeting and care. J Gerontol A Biol Sci Med Sci. 2004;59:255-63.

2. Chen X, Mao G, Leng SX. Frailty syndrome: an overview. Clin Interv Aging. 2014:9:433-41.

3. Fried LP, Tangen CM, Walston J, Newman AB, Hirsch C, Gottdiener J, Seeman T, Tracy R, Kop WJ, Burke G, McBurnie MA. Frailty in older adults: evidence for a phenotype. J Gerontol A Biol Sci Med Sci. 2001;56:M146-56.

4. Morley JE, Vellas B, van Kan GA, Anker SD, Bauer JM, Bernabei R, Cesari M, Chumlea WC, Doehner W, Evans J, et al. Frailty consensus: a call to action. J Am Med Dir Assoc. 2013;14:392-7.

5. Clegg A, Young J, lliffe S, Rikkert MO, Rockwood K. Frailty in elderly people. Lancet. 2013;381:752-62.
6. Collard RM, Boter H, Schoevers RA, Oude Voshaar RC. Prevalence of frailty in community-dwelling older persons: a systematic review. J Am Geriatr Soc. 2012;60:1487-92.

7. Woo J, Yu R, Wong M, Yeung F, Wong M, Lum C. Frailty screening in the community using the FRAlL scale. J Am Med Dir Assoc. 2015;16:412-9.

8. Park SK, Richardson CR, Holleman RG, Larson JL. Frailty in people with COPD, using the National Health and nutrition evaluation survey dataset (2003-2006). Heart Lung. 2013;42:163-70.

9. Lahousse L, Maes B, Ziere G, Loth DW, Verlinden VJ, Zillikens MC, Uitterlinden $\mathrm{AG}$, Rivadeneira $\mathrm{F}$, Tiemeier $\mathrm{H}$, Franco $\mathrm{OH}$, et al. Adverse outcomes of frailty in the elderly: the Rotterdam study. Eur J Epidemiol. 2014;29:419-27.

10. Walston J, Hadley EC, Ferrucci L, Guralnik JM, Newman AB, Studenski SA Ershler WB, Harris T, Fried LP. Research agenda for frailty in older adults: toward a better understanding of physiology and etiology: summary from the American Geriatrics Society/National Institute on Aging research conference on frailty in older adults. J Am Geriatr Soc. 2006:54:991-1001.

11. Singer JP, Lederer DJ, Baldwin MR. Frailty in pulmonary and critical care medicine. Ann Am Thorac Soc. 2016;13:1394-404.

12. Vaz Fragoso CA, Enright PL, McAvay G, Van Ness PH, Gill TM. Frailty and respiratory impairment in older persons. Am J Med. 2012;125:79-86.

13. Choudhury G, Rabinovich R, MacNee W. Comorbidities and systemic effects of chronic obstructive pulmonary disease. Clin Chest Med. 2014;35:101-30.

14. Agusti AG, Noguera A, Sauleda J, Sala E, Pons J, Busquets X. Systemic effects of chronic obstructive pulmonary disease. Eur Respir J. 2003;21:347-60.

15. Marengoni A, Vetrano DL, Manes-Gravina E, Bernabei R, Onder G, Palmer K. The relationship between COPD and frailty: a systematic review and metaanalysis of observational studies. Chest. 2018;154:21-40.

16. Galizia G, Cacciatore F, Testa G, Della-Morte D, Mazzella F, Langellotto A, Raucci C, Gargiulo G, Ferrara N, Rengo F, Abete P. Role of clinical frailty on long-term mortality of elderly subjects with and without chronic obstructive pulmonary disease. Aging Clin Exp Res. 2011:23:118-25.

17. Bernabeu-Mora R, Garcia-Guillamon G, Valera-Novella E, Gimenez-Gimenez LM, Escolar-Reina P, Medina-Mirapeix F. Frailty is a predictive factor of readmission within 90 days of hospitalization for acute exacerbations of chronic obstructive pulmonary disease: a longitudinal study. Ther Adv Respir Dis. 2017;11:383-92.

18. Buckinx F, Rolland Y, Reginster JY, Ricour C, Petermans J, Bruyere O. Burden of frailty in the elderly population: perspectives for a public health challenge. Arch Public Health. 2015;73:19.

19. Walston J, Buta B, Xue QL. Frailty screening and interventions: considerations for clinical practice. Clin Geriatr Med. 2018;34:25-38.

20. Cesari M, Demougeot L, Boccalon H, Guyonnet S, Abellan Van Kan G, Vellas B, Andrieu S. A self-reported screening tool for detecting communitydwelling older persons with frailty syndrome in the absence of mobility disability: the FiND questionnaire. PLoS One. 2014;9:e101745.

21. Chavannes N, Stallberg B, Lisspers K, Roman M, Moran A, Langhammer A, Crockett A, Cave A, Williams S, Jones R, et al. UNLOCK: uncovering and noting long-term outcomes in COPD to enhance knowledge. Prim Care Respir J. 2010;19:408

22. Jones PW, Harding G, Berry P, Wiklund I, Chen WH, Kline Leidy N. Development and first validation of the COPD assessment test. Eur Respir J. 2009;34:648-54.

23. Bestall JC, Paul EA, Garrod R, Garnham R, Jones PW, Wedzicha JA. Usefulness of the Medical Research Council (MRC) dyspnoea scale as a measure of disability in patients with chronic obstructive pulmonary disease. Thorax. 1999:54:581-6.

24. Vogelmeier CF, Criner GJ, Martinez FJ, Anzueto A, Barnes PJ, Bourbeau J, Celli BR, Chen R, Decramer M, Fabbri LM, et al. Global strategy for the diagnosis, management, and prevention of chronic obstructive lung disease 2017 report. GOLD executive summary. Am J Respir Crit Care Med. 2017;195:557-82.

25. The Improvement Hub (ihub). Frailty screening and assessment tools comparator. Healthcare improvement Scotland 2017.

26. Limpawattana $\mathrm{P}$, Putraveephong $\mathrm{S}$, Inthasuwan $\mathrm{P}$, Boonsawat $\mathrm{W}$, Theerakulpisut D, Chindaprasirt J. Frailty syndrome in ambulatory patients with COPD. Int J Chron Obstruct Pulmon Dis. 2017;12:1193-8.

27. Maddocks M, Kon SS, Canavan JL, Jones SE, Nolan CM, Labey A, Polkey MI, Man WD. Physical frailty and pulmonary rehabilitation in COPD: a prospective cohort study. Thorax. 2016;71:988-95.

28. Bone AE, Hepgul N, Kon S, Maddocks M. Sarcopenia and frailty in chronic respiratory disease. Chron Respir Dis. 2017;14:85-99. 
29. Cawthon PM, Marshall LM, Michael Y, Dam TT, Ensrud KE, Barrett-Connor E, Orwoll ES. Frailty in older men: prevalence, progression, and relationship with mortality. J Am Geriatr Soc. 2007;55:1216-23.

30. Kiely DK, Cupples LA, Lipsitz LA. Validation and comparison of two frailty indexes: the MOBILIZE Boston study. J Am Geriatr Soc. 2009;57:1532-9.

31. Cruz-Jentoft AJ, Baeyens JP, Bauer JM, Boirie Y, Cederholm T, Landi F, Martin FC, Michel JP, Rolland Y, Schneider SM, et al. Sarcopenia: European consensus on definition and diagnosis: report of the European working group on sarcopenia in older people. Age Ageing. 2010;39:412-23.

32. Kojima G, lliffe S, Walters K. Smoking as a predictor of frailty: a systematic review. BMC Geriatr. 2015;15:131.

33. Multimorbidity: Clinical assessment and management. NICE guideline [NG56]. 2016

34. Sinclair A, Morley JE, Rodriguez-Manas L, Paolisso G, Bayer T, Zeyfang A, Bourdel-Marchasson I, Vischer U, Woo J, Chapman I, et al. Diabetes mellitus in older people: position statement on behalf of the International Association of Gerontology and Geriatrics (IAGG), the European diabetes working Party for Older People (EDWPOP), and the international task force of experts in diabetes. J Am Med Dir Assoc. 2012;13:497-502.

Ready to submit your research? Choose BMC and benefit from:

- fast, convenient online submission

- thorough peer review by experienced researchers in your field

- rapid publication on acceptance

- support for research data, including large and complex data types

- gold Open Access which fosters wider collaboration and increased citations

- maximum visibility for your research: over $100 \mathrm{M}$ website views per year

At $\mathrm{BMC}$, research is always in progress.

Learn more biomedcentral.com/submissions 